\title{
CUATRO GRABADOS SACROS DE LAS DIVINAS NUPCIAS DE BENITO ARIAS MONTANO*
}

\author{
por José Maria Morillas Alcazar
}

\section{R E S U M E N}

En el presente estudio abordamos el análisis artístico, iconográfico e iconológico de cuatro grabados sacros pertenecientes a la obra "Las Divinas Nupcias" de Benito Arias Montano. Los citados grabados fueron realizados por Philippe Galle e impresos por Cristóbal Plantino. En ellos se muestra un interesante repertorio de formas e influencias artísticas que van desde las italianas hasta las germanas, con un mayor predominio de las primeras.

The present study offers an artistic, iconographic and iconological analysis of four sacred engravings corresponding to "Las Divinas Nupcias", a work by Benito Arias Montano. The engravings were produced by Philippe Galle and printed by Cristóbal Plantino, and display an interesting repertoire of artistic forms and influences ranging from Italian to German, with a greater predominance of the former.

Benito Arias Montano nace en Fregenal de la Sierra en 1527. Es, por tanto, sevillano de nacimiento, ya que la citada localidad, por entonces, pertenecía a esta provincia. De aquí que su partida de nacimiento se encuentre en el Archivo Municipal Hispalense ${ }^{1}$. Su actividad profesional le sitúa como una de las figuras más destacadas de las Artes, el Pensamiento y las Letras del siglo XVI español. Muere en Sevilla en 1598, a la edad de 71 años y sus restos reposan, actualmente, en el Panteón de Sevillanos Ilustres de nuestra capital ${ }^{2}$.

En 1568 Felipe II le comisiona para supervisar la nueva edición políglota, en Amberes, de la denominada Biblia Regia. Esta edición se realizó en ocho volúmenes y ocupó un período cronológico de tres años, de 1569 a $1572^{3}$.

* El estudio general puede encontrarse en la obra de UÑA JUÁREZ; Octavio, HERRERO PEREYRA, Celia y José María MORILlAS ALCÁZAR: Las Divinas Nupcias de Benito Arias Montano. Ediciones Clásicas. Madrid, 1990 (en prensa).

1. (A)rchivo (M)unicipal de (S)evilla. Papeles del Conde del Aguila. Sección XI. Tomo 8. ${ }^{\circ}$, fols. 1-11.

2. BERNALES BALLESTEROS, Jorge: "Retablos y esculturas" en Universidad de Sevilla: patrimonio monumental y artistico. Sevilla, 1986, ps. 89-91.

3. ABELlÁ, José Luis: Historia Crítica del Pensamienno Español. Tomo Il. Madrid, 1979. p. 232. 
Este viaje a Amberes fue fundamental para Arias Montano, ya que allí contactó con Cristóbal Plantino, prototipógrafo del rey. El citado Plantino es un impresor de origen francés, que en 1549 se traslada a Amberes como encuadernador de libros y en 1555 establece su propia editorial. Esta colaboración originó una profunda amistad, que no sólo tuvo consecuencias profesionales, sino también ideológicas. Este cambio ideológico propició en Arias Montano una nueva mentalidad de mayor comprensión y tolerancia. La casa editora Plantino tuvo representantes en Sevilla, debido al auge comercial de nuestra ciudad con Indias. Es por ello por lo que la difusión de estampas y grabados de Plantino llega a Hispanoamérica. Quizás hubiera contactos entre los representantes comerciales de Plantino y Arias Montano en Sevilla, incluso pudo haber una visita del propio Plantino a la capital hispalense. No obstante, entramos en el terreno de la hipótesis, a falta de la documentación correspondiente ${ }^{4}$.

En Amberes, Plantino contactó con Philippe Galle, notable grabador del momento. Galle nació en Harlem (Holanda) en 1537 y murió en la misma ciudad en 1612. Su obra gráfica se especializó en temas históricos, de género y retratos $^{5}$. Actualmente, y tras un análisis de su obra, sabemos que también trató el tema religioso y el profano de inspiración mitológica, siendo las Divinas Nupcias un ejemplo de ello. Philippe Galle perteneció a una familia de grabadores y dibujantes holandeses, realizando su aprendizaje en el taller de Hieronymus Cock en Amberes. Abrió su propio taller en esta ciudad, antes de la muerte de su maestro, y en 1570 se estableció definitivamente en ella ${ }^{6}$.

En consecuencia es lógico que, al vivir en la misma ciudad que Plantino y al poseer un taller de grabados famoso, se establecieran relaciones profesionales entre ambos. De esta colaboración surgieron obras como la que nos ocupa en el presente estudio. El número de grabados realizados por Galle es bastante considerable. Su diseño es correcto, aunque presenta características comunes con los grabadores de su tiempo como una cierta desarmonía y falta de efecto en sus realizaciones ${ }^{7}$.

\section{LAS DIVINAS NUPCIAS}

Las Divinas Nupcias es una colección de poemas realizada por Benito Arias Montano. Se finalizan el 8 de junio de 1573 y se publican en Amberes en 1574. El impresor es Plantino y el grabador Philippe Galle. Su finalidad es

\footnotetext{
4. MORILlas ALCÁZZAR, José María: "Las relaciones entre Arias Montano, Plantino y Galle. La serie de grabados de las Divinas Nupcias" en Las Divinas Nupcias de Benito Arias Montano. (En prensa).

5. BENEZIT, E.: Dictionaire des Peintres, Sculpteurs, Dessinateurs et Graveurs. Vol. II. Paris, 1924, p. 365.

6. THIEME-BECKER: Allgemeines Lexikon der Bildenden Künstler. Vol. XIII. Leipzig, 1920, ps. 105-107.

7. BRYAN, Michael: Dictionary of Painters and Engravers. London, 1873, p. 266.
} 
piadosa y didáctica, siguiendo las directrices de la Iglesia Católica. Se editan con el consentimiento real y eclesiástico. El ejemplar que analizamos se encuentra en la Biblioteca de San Lorenzo del Escorial (Madrid) y proviene de una traducción francesa, ya que el original posiblemente estuvo escrito en su totalidad en latín. Este ejemplar bilingüe está redactado, pués, en francés y en latín. Este último está reservado para los comentarios a pie de ilustración. Su pertenencia a los fondos de la biblioteca escuarialense es lógica, ya que Arias Montano trabajó en ella como bibliotecario. En dicha biblioteca formó y catologó los fondos bibliográficos por orden de Felipe II, tras su regreso de Amberes.

La obra se divide en dos partes conectadas, pero independientes. En la primera de ellas el contenido es alegórico, ya que el Rey de los Reyes preocupado por las licencias del género humano va llamando a las almas. Acude una de ellas, la que ha sido instruida en el temor del Señor, en la disciplina, en la justicia, en la penitencia y en la ciencia. Y en siete tabernáculos se representan los peligros que pueden acechar a las almas y arrastrarlas a la muerte permanente. Se consigna en la introducción de la obra como en un libro aparte se contemplan la vida, hechos y Pasión de Cristo, para servir de ejemplo.

La serie de la vida de Cristo es la que ahora nos interesa para su análisis. En ella se especifica que las láminas están grabadas en cobre por P. Galle, cantadas por Benito Arias Montano y explicadas en rima francesa por P. Heyns. Consta de cuarenta y nueve grabados sobre la vida de Cristo. A estos hay que sumar dos grabados más introductorios. El primero de ellos muestra a Adán y Eva, y el segundo es una representación del rostro de Cristo. La serie se inicia con la Anunciación y termina con Pentecostés. Estos grabados, por tanto, se fechan en 1573 y no como se alude en el Bryan's Dictionary of Painters and Engravers en 1580. Este mismo autor indica como los grabados de esta obra se realizaron en veintiocho planchas ${ }^{8}$.

Las estampas con los pasajes de la vida de Cristo van numeradas. A continuación analizaremos los números 21, 23, 33 y 35 .

$\left.10^{\circ}\right)$ EXPULSIÓN DE LOS MERCADERES DEL TEMPLO (número 21 de la serie sacra). (Lám. 1).

Este episodio, que recoge la expulsión de los mercaderes del templo, se refleja en el siguiente pasaje evangélico: "Llegaron a Jerusalén, entró en el templo y se puso a echar a los que vendian y a los que compraban alli, volcando las mesas de los cambistas y los puestos de los que vendian palomas; y no consentía que nadie transportase objetos atravesando el templo. Luego se puso a enseñar diciendo: ¿No está escrito: «Mi casa será casa de oración para todos los pueblos»? Pues vosotros la tenéis convertida en una cueva de bandidos"9.

8. Ibídem, p. 266

9. San Marcos 11,15-17. 
La escena se ubica dentro de una arquitectura robusta y solemne, cuyos vanos y elementos de sostén marcan la perspectiva y puntos de fuga, logrando el ritmo macizo-vano. Los personajes, tomados con un punto de vista bajo, adquieren un carácter monumental. De ahí que las figuras adopten el canon manierista de alargamiento y la robustez de progenie miguelangelesca. El sabor italiano está más acentuado en los personajes principales, y en los que aparecen de espaldas al espectador. Sin embargo, los secundarios y, especialmente, los barbados responden más al gusto alemán.

La escena evangélica que nos ocupa adopta una composición triangular invertida, para subrayar el dinamismo y violencia de la misma. Por las escalinatas del templo caen, en acentuados escorzos, mercaderes y animales, así como diversos objetos, fustigados por un Cristo justiciero que empuña el látigo en su mano derecha. Mientras que los sumos sacerdotes y letrados contemplan sorprendidos los hechos y esperan un mejor momento para la venganza. Por ello, al pie del grabado se recoge esta leyenda latina como máxima explicativa: "Rem populi expurgare sui, amouisse prophanis qui sacra sic potuit, Rex erat atque Deus" (Quien así pudo corregir la situación de su pueblo y separar las cosas sagradas de las profanas, era Rey y Dios).

Por último, sólo debemos reseñar que esta estampa de la Expulsión de los mercaderes del templo de Jerusalén se hace eco de los viajes que Philippe Galle realizó por Italia y Alemania, tras abrir su taller de grabados en Amberes ${ }^{10}$. Por tanto, esta representación está impregnada, como comentamos anteriormente, de manierismo italiano con algunos matices germanos.

2. ${ }^{\circ}$ EL LAVATORIO. (número 23 de la serie sacra). (Lám. 2).

Esta lámina recoge la narración de San Juan referente al pasaje evangélico del lavatorio. Textualmente, alude a la traición de Judas y comenta como al intentar Cristo lavar los pies a Simón Pedro, éste le dijo:

-Señor, ¿tú lavarme los pies a mí?

Jesús le replicó:

-Lo que yo estoy haciendo no lo entiendes ahora; lo comprenderás más tarde. Replicó Pedro:

- ¿Lavarme tú los pies? Jamás.

Jesús le contestó:

-Si no te dejas lavar, no tienes nada que ver conmigo.

Simón Pedro le dijo:

-Señór, no sólo los pies, también las manos y la cabeza.

Jesús le contestó:

10. THIEME-BECKER: Op. cit., p. 105. 
-Uno que se ha bañado no necesita lavarse más que los pies; está limpio todo. También vosotros estáis limpios, aunque no todos ${ }^{11}$.

El lavatorio se desarrolla dentro de una arquitectura solemne, pesada, de fuertes reminiscencias clásicas. En ella se emplean columnas de orden dóricotoscano sobre altos basamentos. Al fondo, a través de un mirador, se abre una perspectiva urbana. Las figuras adoptan, de nuevo, una robustez que las emparenta con lo miguelangelesco. Esto último se aprecia especialmente en el apóstol Juan que se incorpora para que Cristo le lave los pies, cuando termine con los de Pedro. No obstante, este grabado se basa en una estampa procedente de talleres venecianos, como los difundidos por la casa Corner. La estampa-modelo se inspira directamente en la obra del mismo título del manierista veneciano Jacopo Tintoretto.

El grupo presenta un marcado desarrollo longitudinal; con los personajes dispuestos en dos bandas paralelas, que forman con la arquitectura de fondo una lograda superposición de planos.

La citada concordancia con el lienzo de Tintoretto aparece en el desplazamiento de la escena principal, formada por San Pedro y Cristo. Aunque en este caso, no tan pronunciado comò en el primero. El resto de los personajes se agrupan de una manera distinta, se posterga la mesa sobre la que se acaba de celebrar la Cena, pero se respetan elementos arquitectónicos, como las columnas dórico-toscanas sobre basamentos. $Y$, además, se añade una figura femenina, de estirpe clásica, que porta un jarro con agua ${ }^{12}$.

Al pie de este grabado aparece la inscripción latina: "Extremi exemplum fert dum Praeceptor amoris, examen veri discipuli statuit" (Mientras el Maestro da ejemplo de un extremado amor, instituye un examen del verdadero discípulo).

3. ${ }^{\circ}$ LA FLAGELACIÓN. (número 33 de la serie sacra). (Lám. 3).

Esta escena aparece reflejada en el Evangelio de San Juan, cuando Jesús está en casa del gobernador de Roma: "Entonces Pilato mandó azotar a Jesús. Los soldados trenzaron una corona de espino y se la pusieron en la cabeza, lo vistieron con un manto color púrpura y, acercándose a él, le decían:

- Salud, rey de los judios!

$Y$ le daban bofetadas ${ }^{13}$.

La composición se enmarca dentro de una arquitectura que presenta los mismos rasgos comentados anteriormente, robustez de volúmenes e impronta de origen clásico. La escena se articula con los personajes formando dos grupos conectados, pero independientes. El grupo central está formado por Cristo atado a la columna azotado por dos sayones. Jesús adopta una disposición central, en

11. San Juan 13, 1-17.

12. MORILLAS ALCAZAR, José María: Op. cit.

13. San Juan 19, 1-3 
torno al cual giran los dos soldados. La actitud corporal de los tres personajes es forzada, con valientes escorzos de ascendencia manierista, emparentada con lo miguelangelesco. La pose adoptada y el tratamiento figurativo es casi escultórico, debido a la potencia volumétrica y corporeidad de los personajes. El grupo secundario está formado por cuatro personajes emparejados, que crean una composición en semicírculo. Tras los dos grupos se desarrolla la arquitectura que, de nuevo, insiste en el ritmo macizo-vano. Los vanos abren a unas perspectivas urbanas, actuando como miradores. En uno de ellos, el pueblo de Jerusalén espera la decisión de Pilato. Jesús no muestra aún el manto púrpura ni la corona de espino, ya que la flagelación es previa a la burla. Estilísticamente, en esta escena se realiza un estudio anatómico del natural.

No obstante, sin contradecir lo apuntado anteriormente, es éste uno de los grabados que recoge con mayor claridad la influencia germánica. Como ya mencionamos, Philippe Galle realizó viajes no sólo por Italia, sino también por Alemania. Aquí, posiblemente, vió la obra de los grabadores alemanes, sobre todo la de Alberto Durero, que es la que con seguridad le inspiran al realizar esta plancha ${ }^{14}$.

Bajo la escena se recoje la inscripción: "Ergo ignominiam, ciui quam nulla notat lex, hanc Regi aterno crimina nostra ferunt?” (¿Así pues, nuestros pecados llevaron al Rey eterno esta ignominia que ninguna ley marca para el ciudadano?). (Lám. 4).

$4^{\circ}$ ) PRESENTACIÓN AL PUEBLO. (número 35 de la serie sacra).

Esta estampa recoge el pasaje evangélico de San Juan: "Pilatos salió otra vez afuera y les dijo:

-Mirad, os lo saco fuera para que sepáis que no encuentro ningún cargo contra él. Salió Jesús llevando la corona de espino y el manto color púrpura. Pilatos les dijo: -Aquí teneis al hombre.

Al verlo, los sumos sacerdotes y los subalternos gritaron:

- ¡A la cruz! ¡A la cruz!

Pilatos les contestó:

-Lleváoslo vosotros y crucificadlo; yo no encuentro ningún cargo contra él'15.

La escena se desarrolla en el recinto urbano de Jerusalén. A través de una perspectiva oblícua se llega a una arquitectura centrada, que representa el templo de aquella ciudad. Este edificio sagrado está realizado con planta y alzado circular. En ello encontramos un claro precedente pictórico italiano, al tomar como base dos composiciones: la del Perugino, en "La entrega de las llaves a San

14. MORILlAS ALCÁZAR, José María: Op. cit.

15. San Juan 19,4-6. 
Pedro" (pintura al fresco de la Capilla Sixtina); y la de su discípulo Rafael, en "Los desposorios de la Virgen" (óleo sobre tabla de la Pinacoteca Brera de Milán). No obstante, el modelo arquitectónico se acerca más a esta última, con pequeñas variantes, al situar una escalinata de acceso al recinto sacro ${ }^{16}$.

A ambos lados de esta arteria viaria, que conduce al templo, se desarrolla la acción. En la zona derecha, destaca el Palacio del Pretorio, desde el que Pilato, acompañado por la guardia pretoriana, hace elegir al pueblo entre Cristo y Barrabás. Los protagonistas de la escena, Pilato y Cristo, se representan de cuerpo entero, a la derecha de la composición. Jesús junto a la columna queda interpretado como eje del Universo. En un segundo plano, detrás, aparece Barrabás custodiado por la guardia. Ante Jesús, ocupando la vía pública, a la izquierda del grabado, se aglomera la multitud que grita y gesticula groseramente, pidiendo a Poncio Pilato la crucificción del Redentor. Contrastando con la factura grotesca de estos personajes del pueblo llano, aparece un segundo friso de figura aúlicas de marcado clasicismo.

En esta obra el eclecticismo de su autor se refleja nuevamente en la solución de compromiso que busca el equilibrio entre las fórmulas italianas y germanas. Influencias que quedan patentes no sólo en el estudio morfológico e iconográfico de los personajes, sino también en la sabia conjunción tipológica de los edificios, que componen el solemne marco arquitectónico donde se desenvuelve el episodio evangélico, que queda sintetizado en la leyenda impresa a pie de lámina. Textualmente dice: "Dum sernatorem repulisti infide, Salutem abiecisse tuam scilicet argueris" (Traidor, al rechazar al Salvador demuestras claramente que rechazas tu salvación).

16. MORILLAS ALCÁZAR, José Maria: Op. cit. 


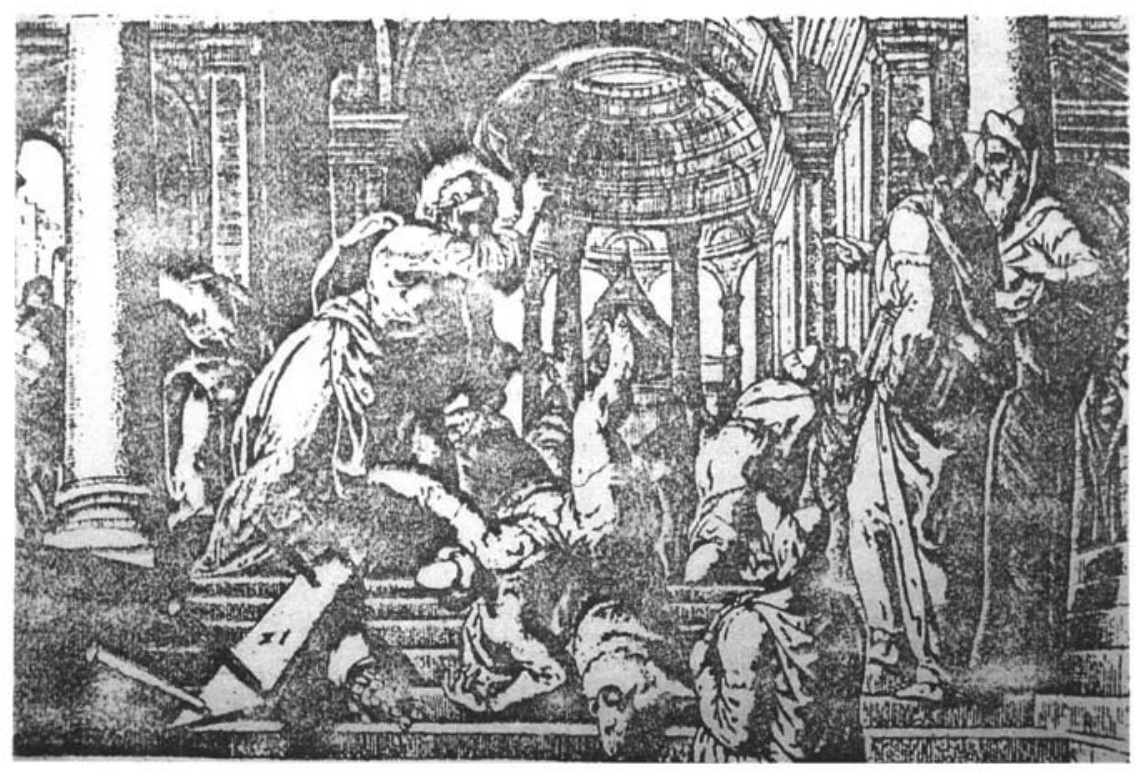

Läm. I

Expulsión de los mercaderes del templo (número 21 de la serie sacra). 


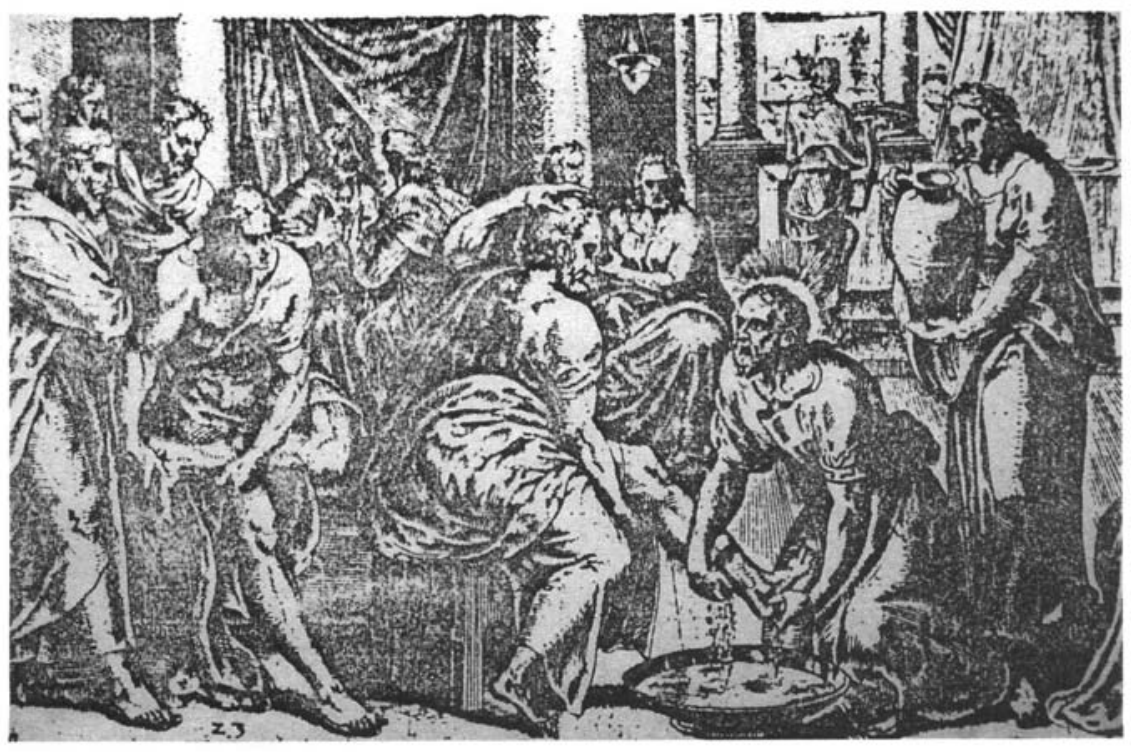

Lám. 2 


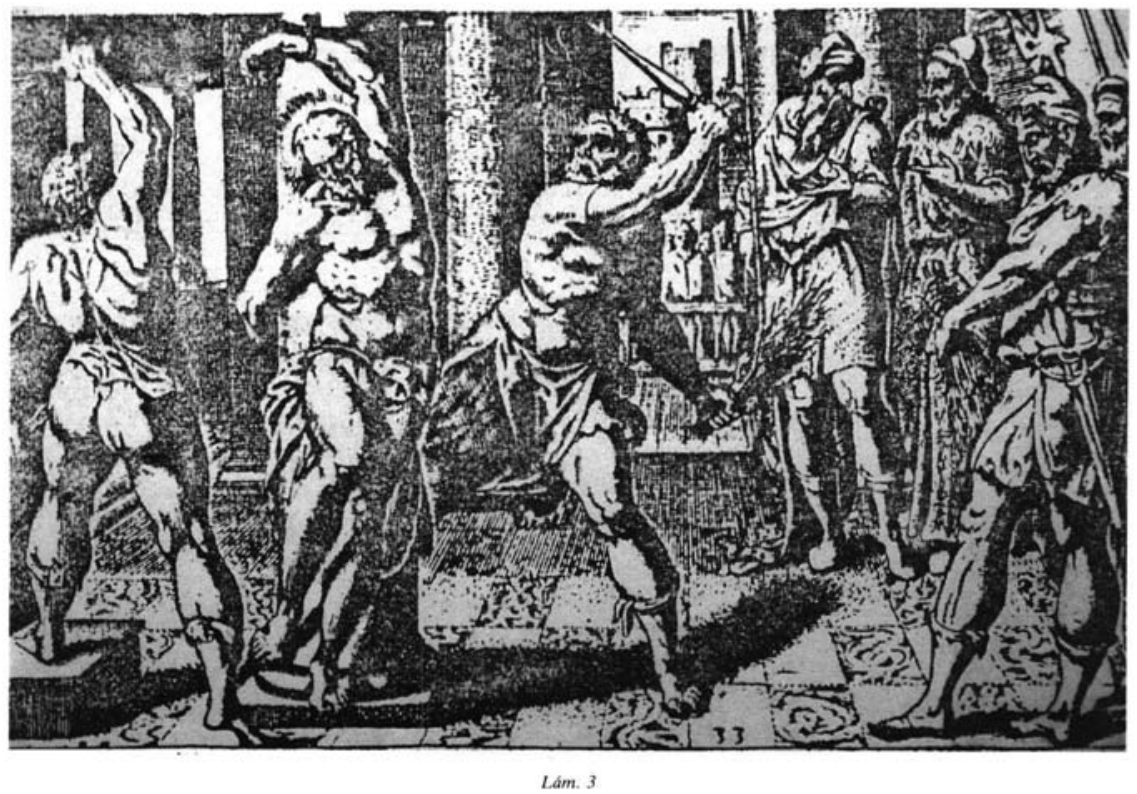

La Flagelación. (número 33 de la serie sacra) 


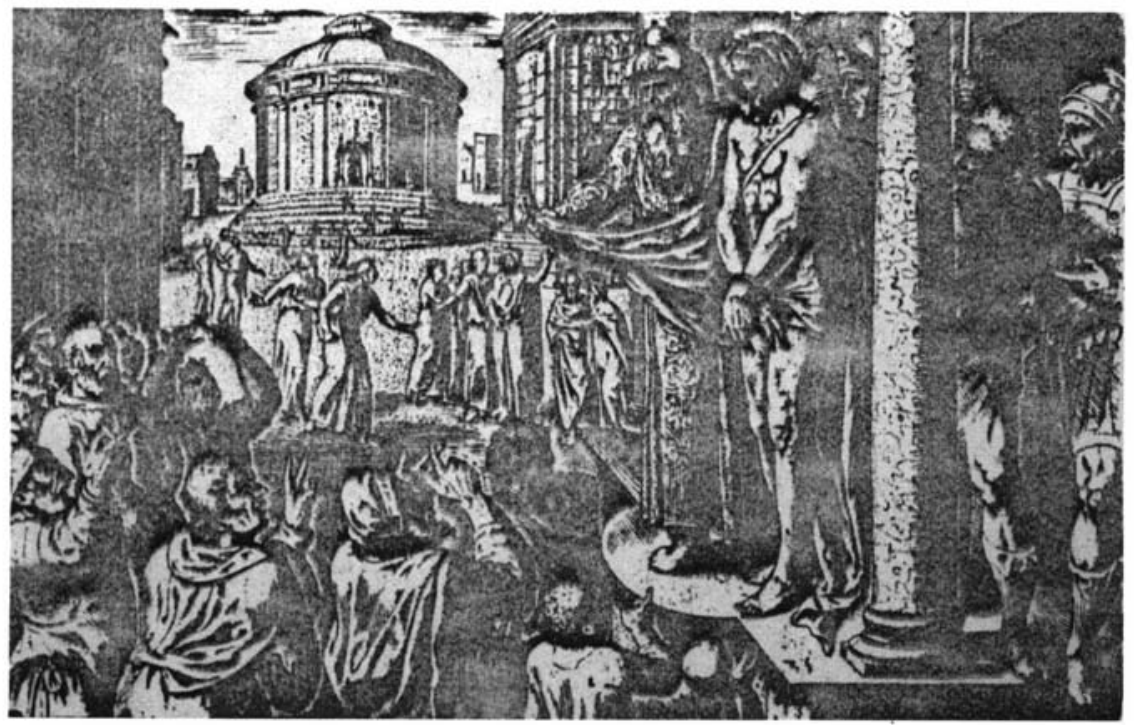

Lam. 4 